\title{
Study on the Failure Mechanism of Frame Structure under the Diluted Debris Flow Impact
}

\author{
Peizhen LI \\ Research Institute of Structural Engineering and Disaster \\ Reduction \\ Tongji University \\ Shanghai, China \\ e-mail: lipeizh@tongji.edu.cn
}

\author{
Shanhua YANG \\ Research Institute of Structural Engineering and Disaster \\ Reduction \\ Tongji University \\ Shanghai, China \\ e-mail:yshhua@sina.cn
}

\author{
Xilin LU \\ Research Institute of Structural Engineering and Disaster Reduction \\ Tongji University \\ Shanghai, China \\ e-mail: 1xlst@ tongji.edu.cn
}

\begin{abstract}
A three-dimensional reinforced concrete frame structure under diluted debris flow impact was established using explicit dynamic analysis finite element software LS DYNA. The dynamic damage distribution and stress redistribution process of the structure under the impact were calculated and analyzed. The results show that, under the impact of the diluted debris flow, the bottom columns of the frame fail to work, and the original path of the force transmission is changed. Under the continuous impact, the plastic damage in the structure accumulates with the stress concentration being deepened and the displacement of the structure increasing, making the ability of the structure to resist the impact decrease. The failure form of reinforced concrete frame under diluents debris flow impact is shear type.
\end{abstract}

Keywords-component; frame structure; debris flow; impact force; $L S-D Y N A$

\section{INTRODUCTION}

Debris flow is a natural disaster with high frequency in the western China, which is a serious threat to the life and property of the local people. As the ability of structures in the villages and towns to resist geological disasters is generally low, especially the resistance ability of the local office buildings and the houses to the debris flow disaster is poor [1]; the research for the mechanism of the structure damage under the impact of debris flow is of great significance.

Large rock in the debris flow is the most critical factor for building damage, which must be considered in the construction [2]. In addition, mud, as an important part of debris flow, must be taken full consideration in the research.

Frame structure is one of the typical structure types in the western China. Bottom frame columns are key links in the force path from top to bottom [3]. Under the impact of debris flow, if they are destroyed first, the force path will be changed, which will result in the destruction of the adjacent structural members and the collapse of the whole structure [4]. Therefore, the research emphasizes both on the whole response of frame structure under the impact of debris flow and the failure mode of the bottom frame columns. By using the explicit dynamic finite element analysis software LSDYNA, the paper established a three-dimensional finite element model for reinforced concrete frame under the impact of diluted debris flow, and then analyzed the process of the dynamic damage distribution evolution and internal force redistribution.

\section{STRUCTURE MODELING METHOD}

\section{A. Programs and Algorithms of LS-DYNA}

LS-DYNA is finite element software famous for its explicit dynamic analysis, which can deal with all kinds of complex nonlinear problems accurately and reliably, such as collision analysis and explosion analysis [5]. It is fully functional software with abilities solving geometric nonlinear, material nonlinear and contact nonlinear proble ms. As its algorithms based on Lagrange with ALE and Euler, solutions based on explicit solution with implicit solution, it is widely used in structural dynamic analys is for its powerful nonlinear dynamic analys is function.

The impact of debris flow on building structural members is essentially a contact-impact problem. In that process, the structure and the load are coupled [6], which can be solved by powerful nonlinear analysis function of LSDYNA. In the software, the finite element models can be established separately for two colliding objects, and then the impact load is solved by the displacement compatibility equations and momentum equations [7, 8].

\section{B. Material Model and Constitutive Relation}

Concrete material was simulated by continuous cap model (*MAT_CSCM_CONCRETE) in LS-DYNA. The failure of concrete was considered by setting the erosion 
coefficient 'erode', with the corresponding failure criterion, the maximum principal strain criterion. When the maximum principal strain exceeded 0.05 , the concrete elements would fail and be removed.

Material model of longitudinal reinforce ment and stirrup used bilinear kinematic hardening elastoplastic model (*MAT_PLASTIC_KINEMATIC). Failure of the reinforced element in the elastoplastic model was considered by setting the failure strain, with the corres ponding failure criterion, the maximum strain criterion of element. When the maximum strain of the elements was more than 0.12 , the reinforcement ele ments would be removed and exit.

Rock was simulated by material model 20 (MAT_RIGID). The elastic modulus of the rock is $5.3 \times 10^{4}$ $\mathrm{MPa}$, and the Poisson's ratio is 0.2 . In the software, in order to ensure the accuracy, it requires that the units' size of primary and secondary contact surface should be close. A method was put forward to simulate the large mass of rock by changing the density of it, in order to avoid a large amount of elements and nodes in the rock model and the increase of computation time, if the rock was simulated by actual density and volume. Therefore, the quality of the rock was $896 \mathrm{~kg}$, as its density was $7000 \mathrm{~kg} / \mathrm{m}^{3}$ and the volume was $0.4 \times 0.4 \times 0.8 \mathrm{~m}^{3}$.

\section{Calculation Method of Debris Flow Slurry Impact Force}

In order to simplify the calculation of slurry hydrodynamic pressure, the following hypotheses were proposed:

(1) The slurry of liquid debris flow was simplified to a uniform one-dimensional Newtonian fluid, and the hydrodynamic pressure of the slurry was reduced to uniform force on the impacted member.

(2) Debris flow was perpendicular to the axis of the column. In addition, the depth of the debris flow was the same as the height of the bottom column, and it were the same along the streamline sections.

On the basis of the assumptions above, the formula (1) was used to calculate the maximum hydrodynamic pressure of the slurry. The formula was derived from the pressure calculation formula in fluid mechanics by multiplying the non-uniformity coefficient $\mathrm{k}$. In the formula, $P$ represents the maximum impact force of debris flow; $k$ is the empirical coefficient; $v$ represents the debris flow velocity.

$$
P=k \rho v^{2}
$$

The slurry impact force, which was loaded on the pillar facing surface of the column, was simplified as the uniform load. The magnitude of the mud impact force was calculated according to formula (1). In the calculation process, only the bottom column in the stationary section of the debris flow was considered, as the leading section was short and unavailable. Therefore, $\mathrm{k}=0.5$ [9] and the calculated results of the mud impact force are shown in the following table.
TABLE I. CALCULATION RESUlt OF SLURRY IMPACT ForCE

\begin{tabular}{|c|c|c|c|}
\hline $\begin{array}{c}\text { Velocity } \\
\mathbf{m} / \mathbf{s}\end{array}$ & $\begin{array}{c}\text { Slurry Density } \\
\mathbf{t} / \mathbf{m m}^{\mathbf{3}}\end{array}$ & $\begin{array}{c}\text { Experiential } \\
\text { Coefficient } \\
\mathbf{k}\end{array}$ & $\begin{array}{c}\text { Slurry Impact } \\
\text { Force } \\
\mathbf{~} \mathbf{N} / \mathbf{m}\end{array}$ \\
\hline 5 & 2.0 & 0.5 & 3 \\
\hline
\end{tabular}

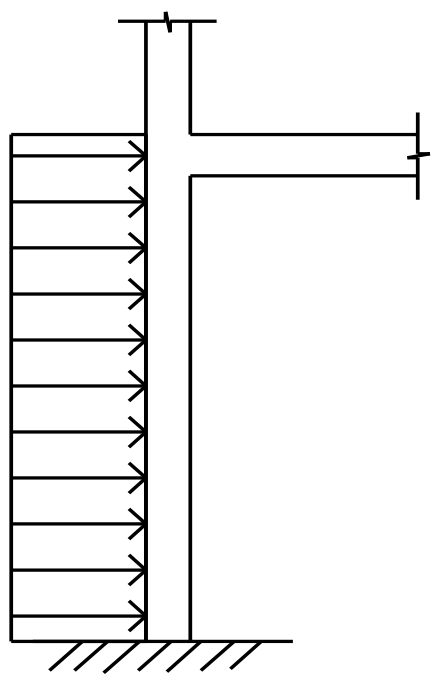

Figure 1. Impact position of debris flow slurry

\section{Simulation Method of Impact Force of Rocks in Debris Flow}

The impact of large rocks in the debris flow is the main reason for structural damage. Most existing formulas for calculating the impact force of debris flow use pseudo-static method to obtain the impact force without taking the time effect of debris flow impact into account [10]. In addition, the various existing calculation models have their own calculation assumptions, making them only be applied to a certain range, while LS-DYNA has a powerful contact analysis capabilities and rich non-linear material library, which makes it possible to simulate the contact-collision problem. Accordingly, LS-DYNA was used to simulate the large rocks in the debris flow directly. The initial velocity of the rock and the contact between the rock and the structure were used to simulate the impact of the rock.

In a dilute debris flow, the rocks are usually run at the bottom of the fluid [11]. Through experimental study, Yang Hongjuan [12] found that rocks in the debris flow mainly concentrated in the $2 / 5 \sim 3 / 5$ of the maximu m flow depth. In Wei Hong's [13] and Huang's [14] opinion, rocks were more concentrated in the $2 / 5 \sim 3 / 5$ of the depth in the diluted debris flow. Proske [15] believed that the maximum impact of debris flow would occur in the 1/5 1/3 of the mud depth. Chao Zeng [16] found that the concentration of rocks in the $1 / 5$ of maximum depth of flow was more unfavorable in the diluted debris flow.

Based on the research results above, the following assumptions were proposed:

(1) The velocity of movement of large rocks in the debris flow was the same as that of the fluid.

(2) Rocks are concentrated in the $1 / 5$ of maximum depth in the debris flow. 


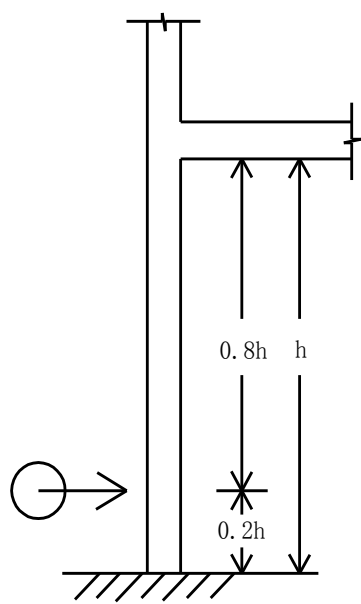

Figure 2. Impact position of the rock

\section{ANALYSES ON AN EXAMPLE}

\section{A. Finite Element Model}

A three-story reinforced concrete frame structure was established. The layout plan and height information of the standard layer are shown in Figure 3. The strength of the structural steel bar was HRB335, the concrete strength was C30, the failure strain was 0.08 , the standard layer dead load was $5 \mathrm{kN} / \mathrm{m}^{2}$, and the live load was $2 \mathrm{kN} / \mathrm{m}^{2}$. Then, the threedimensional finite element model of concrete frame was established by LS-DYNA. In the finite element model, the three-dimensional beam element BEAM161 was used to simulate the reinforced concrete beams and columns. Threedimensional shell element SHELL163 was used to simulate the reinforced concrete slabs, and the three-dimensional eight-node solid element SOLID164 was used to simulate the rock. The finite element model is shown in Figure 4.
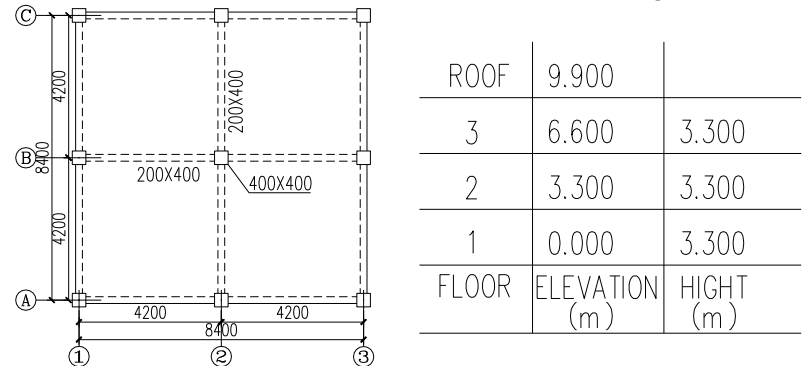

Figure 3. Structure layout of standard layer and height information
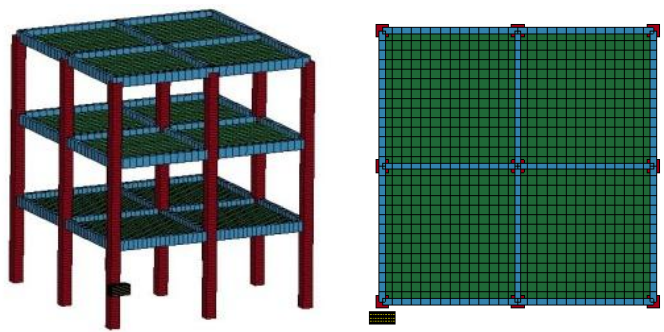

Figure 4. Finite element model of frame structure
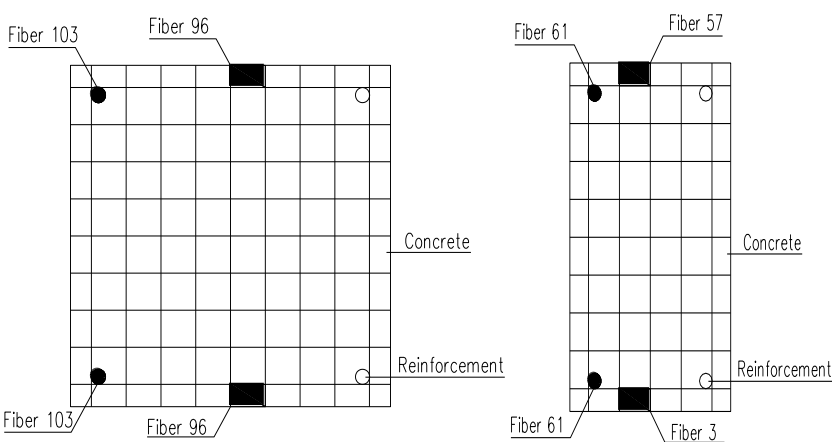

Figure 5. Sectional division of fiber beam element

In the finite element model, material model 124 (MAT_PLASTICITY_COMPRESSION_TENSION) was used to simulate the concrete. The columns and beams were divided into fiber elements. The numbering of the meshing and the partial fibers are shown in Figure 5.

The reinforcement was regarded as an ideal elastoplastic material, whose elastic modulus was $200 \times 10^{9} \mathrm{~Pa}$ and failure strain was 0.11 . The stress -strain curves of the concrete are shown in Figure 6.

The impact force was modeled as described in sections 1.3 and 1.4 above. Rocks impacted twice. The size of the rocks was $0.4 \times 0.4 \times 0.8 \mathrm{~m}^{3}$, with the mass of $896 \mathrm{~kg}$ and the impact speed of $5 \mathrm{~m} / \mathrm{s}$. The impact point was located at the midpoint in $1 / 5$ of the column height. The solution time of the first impact loading was defined as $0.5 \mathrm{~s}$ and the second was $1.0 \mathrm{~s}$.
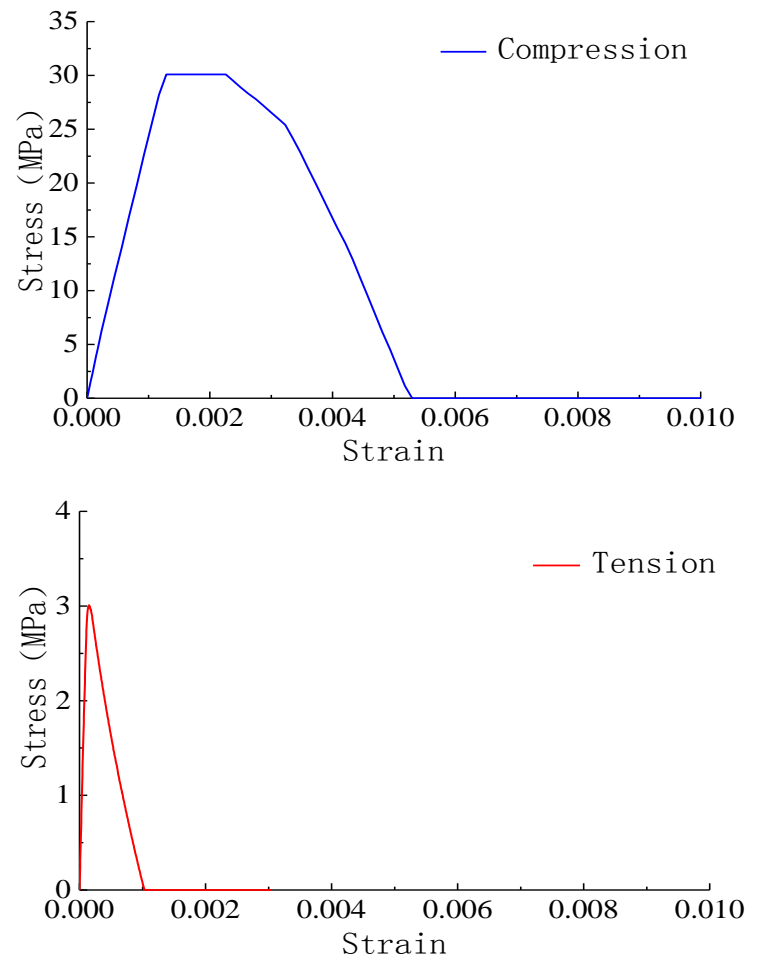

Figure 6. Stress - strain curves of concret 

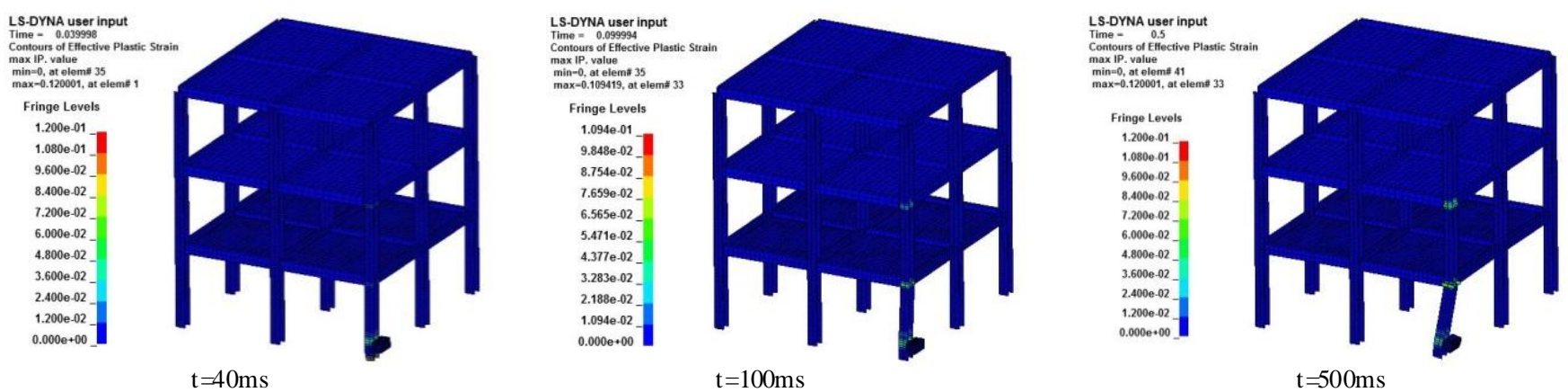

Figure 7. Variation of plastic damage distribution of beams and columns

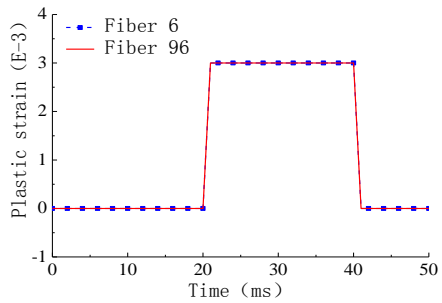

Beam Element 1

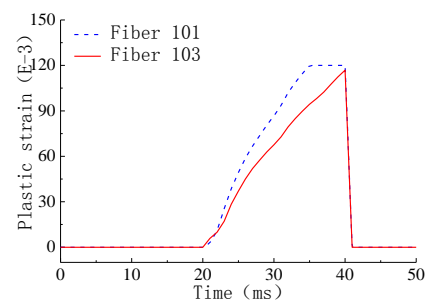

Beam Element 1

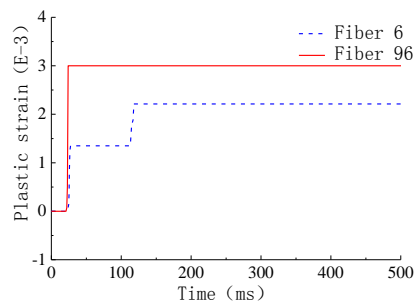

Beam Element 33

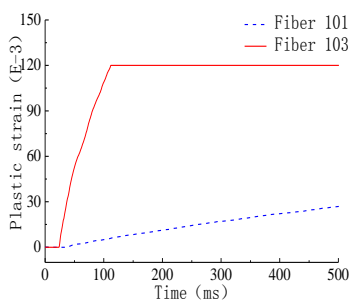

Beam Element 33

Figure 8. Plastics train-time curves of some fibers of the beam elements

\section{B. Calculation Results and Analysis}

1) The calculation results and analyses of the first collision:

\section{a) Dynamic Damage Distribution Process:}

Figure 7 shows the distribution of plastic damage of the frame beams and columns. The plastic strain time-history curves of some fibers in beam elements 1 and 33, located at the support on the bottom and the top of column $\mathrm{C} 1$ (the underlying column at A/1 in Figure 3) are presented in Figure 8 . The position of the studied fibers in the section is shown in Figure 5 above.

As shown in Figure 7 , when $\mathrm{t}=40 \mathrm{~ms}$, the structural plastic damage is mainly concentrated at the collision zone and base bearing of colu mn $\mathrm{C} 1$, as well as the top bearing of column C2. Figure 8 shows that the plastic strain of concrete in beam element 1 reaches 0.003 and the plastic strain of some of the reinforcement reaches 0.12 . When $t=50 \mathrm{~ms}$, the elements fail and are deleted. When $50 \mathrm{~ms}<\mathrm{t}<500 \mathrm{~ms}$, the range of plastic damage is widened and the degree of damage is further deepened. In addition, the plastic damage in the structure is mainly concentrated in the column $\mathrm{Cl}$ and its connected components, while the damage of the other parts is relatively light.

Figure 9 shows that the plastic strain at the bearings of the beams and the columns develops fully after the collision, and most of the reinforcement fibers and concrete fibers have reached the ultimate plastic strain.

\section{b) Internal Force Redistribution Process:}

Figure 9 shows the development of stress in beams and columns at different times. Figure 10 shows the internal force-time-history curves for columns C1, C2 and beams B1, B2.

Figure 9 shows that, at $\mathrm{t}=40 \mathrm{~ms}$, the maximu $\mathrm{m}$ stress area is concentrated in columns $\mathrm{C} 1, \mathrm{C} 2$ and $\mathrm{C} 3$, and the stress at the bottom of the column $\mathrm{C} 1$ and in the direct contact area is the greatest. When $100 \mathrm{~ms}<\mathrm{t}<500 \mathrm{~ms}$, the stress concentration region gradually expands, with the increasing of the degree of stress concentration.

From Figure 10, the internal force of the cross section at the top bearing of the column $\mathrm{Cl}$ has a large fluctuation during the collision, which is the most obvious at first, but the latter regularity of the change is not obvious. From Figure 11 to 12, the bending moment of the bearing of the beam near the column $\mathrm{C} 1$ first increases and then decreases. Although the bending moment direction changes, the absolute value decreases. While the bending moment of the bearing of the beam away from the column $\mathrm{C} 1$ first decreases and then increases, and the bending moment direction is stable after the stabilization with its absolute value decreasing. Accordingly, shear force changes roughly in opposite. This may be due to the fact that, in the initial stage of the collision, a displacement is produced in the bearing of the beam near the column $\mathrm{C} 1$ in accordance with the initial deformation direction, making the bending moment increase. On the other hand, the displacement is opposite to the initial deformation direction in the later stage of the collision, so the bending moment decreases. However, in the initial stage of the collision, the displacement in the bearing of the beam away fro $\mathrm{m}$ the colu $\mathrm{mn} \mathrm{Cl}$ is opposite to the initial deformation direction, making the bending moment decrease. Then, the displacement is in accordance with the initial deformation direction in the later stage of the collision, so the bending moment increases. 

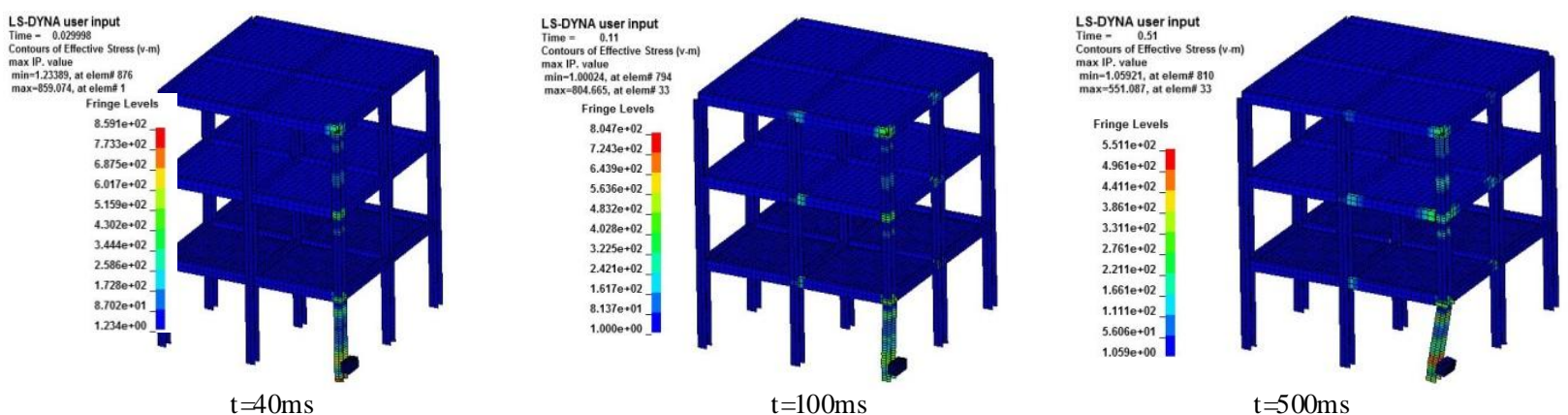

Figure 9. Development of stress of columns and beams
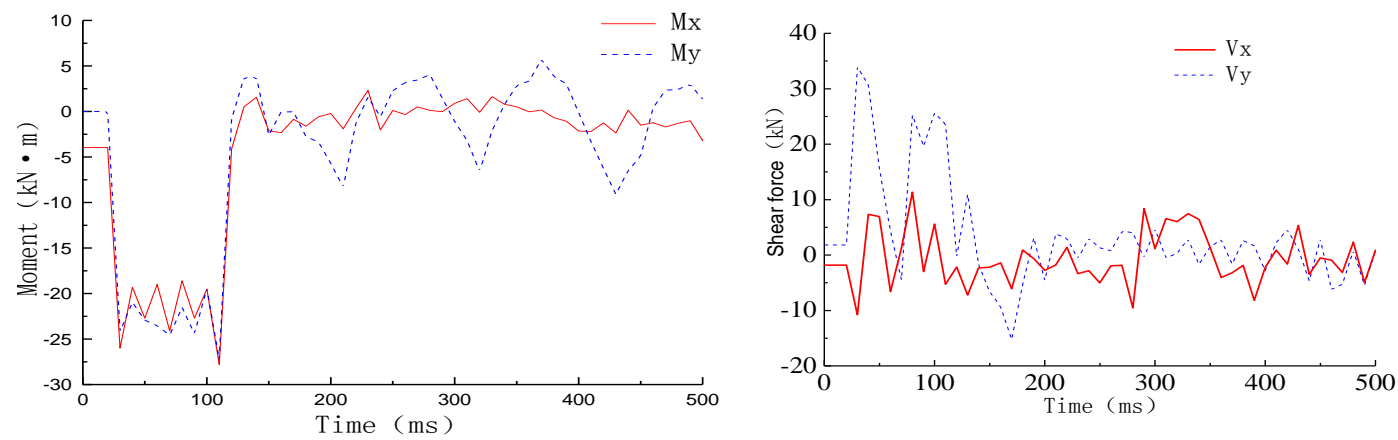

Figure 10. Internal force-time hist ory curve of the section at top of column $\mathrm{Cl}$
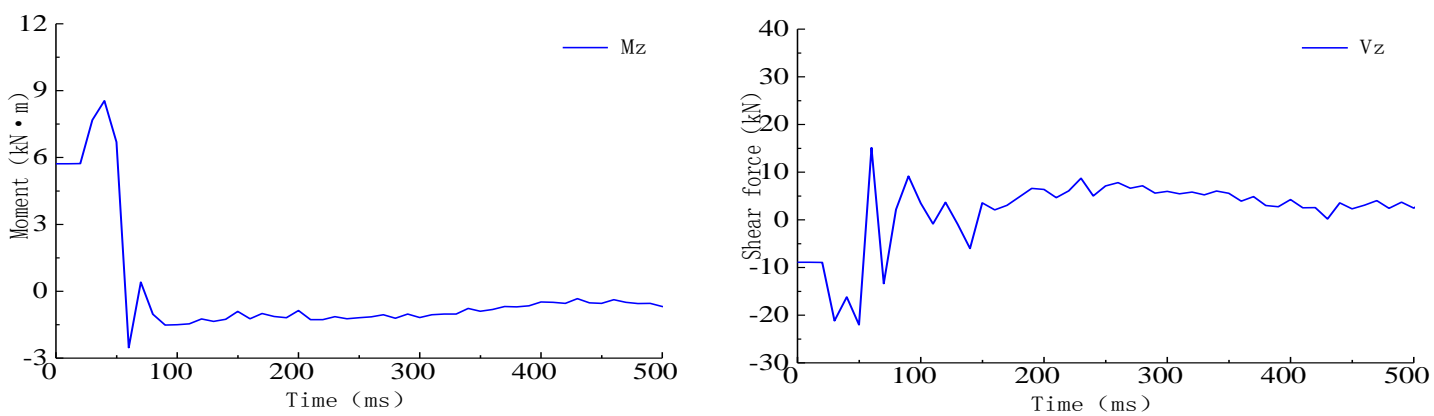

Figure 11. Internal force-time history curve of the beam B1 section near axis A

2) The calculation results and analyses of the second collision:

\section{a) Dynamic Damage Distribution Process:}

Figure 13 shows the distribution of the plastic damage of the frame beams and columns in the second collision.

When $\mathrm{t}=530 \mathrm{~ms}$, it can be seen that there are new areas of plastic damage in the direct impact zone and base bearing of column $\mathrm{C} 4$ (the underlying column at $\mathrm{A} / 2$ ). When $600 \mathrm{~ms}<\mathrm{t}$ $<1100 \mathrm{~ms}$, column C4 is out of work and the range of the cantilevered plate is further enlarged, because of the base bearing failure of the column. It can be obtained that the deflection of beams and slabs is increasing, and the damage area of the structure is also enlarged. Plastic damage occurs in the beam-column nodes far away from the collision zone. When $1100 \mathrm{~ms}<\mathrm{t}<1500 \mathrm{~ms}$, part of the concrete plate is pulled off and the beam-column nodes are disconnected, resulting in the structure entering the local collapse stage.

From the analyses, under the impact of the debris flow, because of the bottom column failing to work, the original path of the force transmission is changed, making the structure occur a great deformation under the loads. Accordingly, plastic damage in the structure also accumulates, leading to partial collapse.

b) Internal Force Redistribution Process:

Figure 14 shows the distribution and variation of stress in beams, columns and concrete slabs at different times.

When $\mathrm{t}=530 \mathrm{~ms}$, on the bas is of the first collision, the area with the greatest stress extends further to the column $\mathrm{C} 4$ and the bottom bearing area, and the stresses at the columns C5 and C6 also increase. When $\mathrm{t}=600 \mathrm{~ms}$, the stress at the distal sections of the beams directly connected to the columns C1 C6 also begins to increase. This indicates that the diffusion path of the impact stress in the structure is first propagated through the direct contact zone, then upwards, and then gradually towards both sides. When $900 \mathrm{~ms}<\mathrm{t}$ $<1500 \mathrm{~ms}$, the stress concentration area expands further, stress concentration gradually increases, and the structure occurs a large vertical displace ment under the loads. 


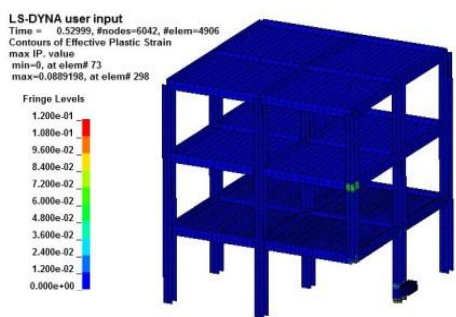

$\mathrm{t}=530 \mathrm{~ms}$

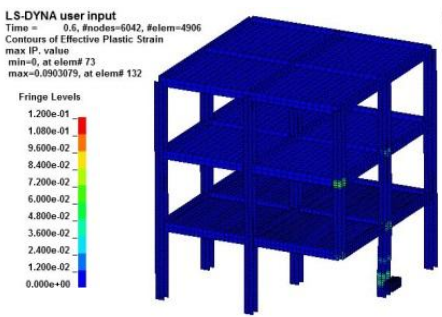

$\mathrm{t}=600 \mathrm{~ms}$

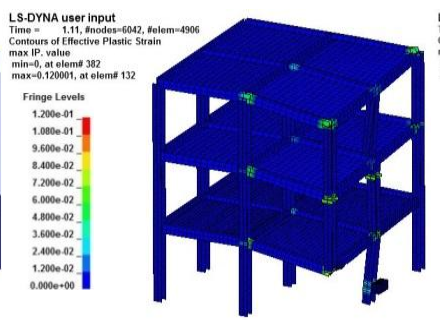

$\mathrm{t}=1110 \mathrm{~ms}$

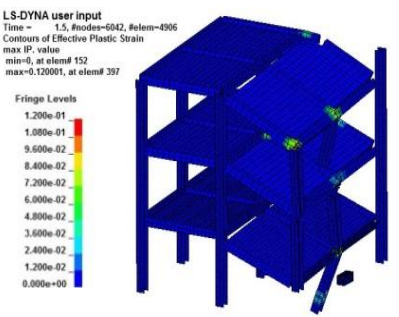

$\mathrm{t}=1500 \mathrm{~ms}$

Figure 12. Variation of plast ic damage distribution of beams and columns

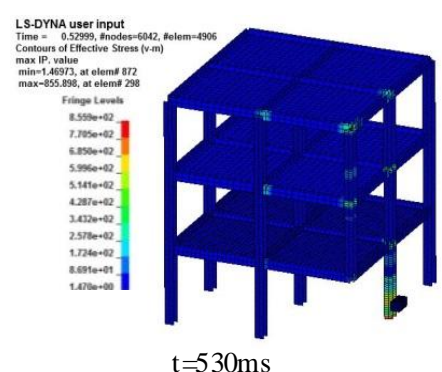

$\mathrm{t}=530 \mathrm{~ms}$

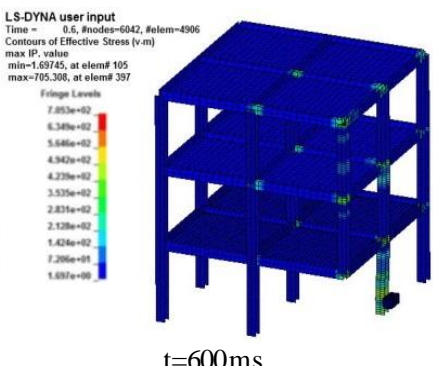

$\mathrm{t}=600 \mathrm{~ms}$

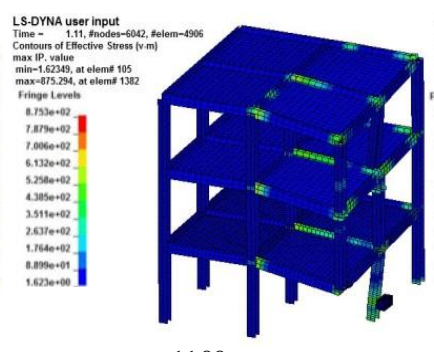

$\mathrm{t}=1100 \mathrm{~ms}$

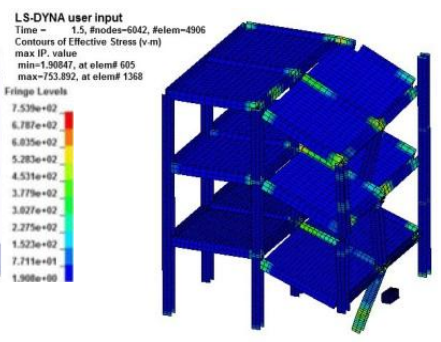

$\mathrm{t}=1500 \mathrm{~ms}$

Figure 13. Development of stress of columns and beams

\section{CONCLUSIONS}

LS-DYNA is used to calculate and analyze the failure mechanism of a three-story RC frame structure under the impact of diluted debris flow in the paper. It is discussed that the distribution of internal dynamic damage and the process of internal force redistribution during the impact of the rock, we can get the following conclusions.

(1) The results show that, under the impact of the diluted debris flow, the bottom columns of the frame fail to work, and the original path of the force transmission is changed. Under the continuous impact of rocks, the plastic damage in the structure accumulates with the stress concentration being deepened and the displacement of the structure increasing under loads, making the ability of the structure to resist the impact decrease. Local collapse may occur in more severe cases.

(2) Under the impact of diluted debris flow, the failure mode of reinforced concrete frame is shear type, because of the impact position of rocks near the bottom of the colu mn.

(3) Flexible materials can be used on the surface of the bottom columns to reduce the impact of the large rocks, such as waste tires, polyurethane steel plywood materials.

\section{ACKNOWLEDGMENT}

This project was supported by the National Key Technology R\&D Program (Grant No. 2014BAL05B01).

\section{REFERENCES}

[1] KANG Zhi-cheng, LI Zhuo-fen, MA Ai-nai. Debris flow research in China [M]. Beijing: Science Press, 2004.

[2] DI Sheng-kui, LI Jian, ZHANG De-qiang. Damege mechanism of frame structures impacted by debris flow.

[3] LI Jian-zhong, LU Xi-ling LI Xiang, et al. Seismic damage of reinforced concrete frame structure in Wenchuan Earthquake [J]. Struct ural Engineer, 2008,24(3): 9-11.
[4] HU Kai-heng, CUI Peng GE Yong-gang. Building destruction patterns by august 8, 2010 debris flow in Zhouqu, Western China [J]. Journal of Mount ain Science, 2012,30(4): 484-490.

[5] SHI Dang-yong, LI Yu-chun. Explicit dynamic analysis with ANSYS/LS-DYNA 8.1[M]. Beijing: T singhua University Press, 2005.

[6] CHEN Hong-Kai, XIAN Xue-fu, T ANG Hong-mei, et al. Timefrequency analysis method of debris flow impact loads and its applications [J]. Journal of Disaster Prevention and Mitigation Engineering, 2011,31(3): 255-260.

[7] ZHAO Hai-ou. The guide to dynamic analysis with LS-DYNA[M]. Beijing: Weapon Industry Press, 2003.

[8] Hallquist J O. LS-DYNA theory manual [M]. California: Livermore Soft ware Technology Corporation. 2006: 273-277.

[9] CHEN Hong-kai, TANG Hong-mei, XIAN Xue-fu, et al. Experimental model of debris flow impact features [J]. Journal of Chongqing University (Natural Science Edition), 2010, 33(5): 114119.

[10] LI Pei-zhen, GAO Yu, GUO Mo-jun. Research Status and Development Trend of Debris-flow Impact Force [J]. Structural Engineer, 2015,31(1): 200-206.

[11] Hu K, Wei F, Li Y. Real-time measurement and preliminary analysis of debris-flow impact force at Jiangjia Ravine, China [J]. EARTH SURFACE PROCESSES AND LANDFORMS, 2011,36(9):12681278.

[12] YANG Hong-juan, WEI Fang-qiang, HU Kai-heng, et al. Experimental study on vertical sorting of particles in debris flow with impact signals 1 [J]. Journal of Catastrophology, 2011,26(4): 29-34.

[13] WEI Hong. Experimental study on impact force of debris flow heads[J]. China Railway Science,1996,17(3): 50-62.

[14] Proske D, Kaitna R, Suda J, Huebl J. Estimation of a debris flow impact force against protection structures made of struct ural concrete [J]. View ResearcherID and ORCID, 2008, 85(12): 803-811.

[15] Proske D, Suda J U R, H U Bl J. Debris flow impact estimation for breakers [J]. Georisk, 2011, 5(2):143-155.

[16] Zeng C, Cui P, Su Z, et al. Failure modes of reinforced concrete columns of buildings under debris flow impact [J]. Landslides, 2015, 12(3): 561-571. 